\title{
Asymptomatic Extradural Hematoma-Our Observation In DMCH
}

\author{
Das $\mathrm{S}^{1}$, Ghosh $\mathrm{D}^{2}$, Sarkar $\mathrm{AC}^{3}$, Khan $\mathrm{SI}^{4}$
}

Conflict of interest: There is no conflict of interest relevant to this paper to disclose.

Funding Agency : was not funded by any institute or any group.

Contribution of Authors: Principal Investigator and Manuscript preparation-

Data collection-

Scalp block with anaesthesia-

Editorial formatting-

Copyright: @2020bang.BJNS published by BSNS. This article is published under the creative commons CC-BY-NC license. This license permits use distribution (https://creativecommons. orgf/licences/by-nc/4-0/)reproduction in any medium, provided the original work is properly cited and is not used for commercial purposes.

Received: 22.01 .20

Accepted: 26.03 .20

\begin{abstract}
:
Background: Surgical management of extradural hematoma is evacuation of extradural hematoma until otherwise. But, a number of authors have suggested that small epidural hematoma may be managed conservatively with normal outcome in selected cases. The goal of this study was to define the clinical and radiological parameters that may help in the management of the patient with small epidural hematoma where the hematoma was asymptomatic.
\end{abstract}

Objective: This study was conducted to find out the factors influencing the decision making in the management of asymptomatic extradural hematoma though they have no evidence of raised intracranial pressure or any focal neurological deficit.

Methods: Three hundred patients were evaluated clinically and by CT scan of head to see of hematoma, location of hematoma, midline shifting and overlying skull fractures etc.

Results: All 300 patients were diagnosed within 72 hours of trauma and were tired to be managed expectantly but was not possible sometimes. All these patients were analyzed on the basis of tome since trauma, GCS score, overlying skull fracture traversing any artery, vein or any venous sinuses. Among 300 patients 225 (75\%) patients underwent CT scan of head within 24 hours of trauma and 185 (61.67\%) patients had overlying skull fracture. 51 (17\%) deteriorated later on and 31 (10.33\%) patients among them required surgical evacuation of hematoma.

Conclusion: It can be concluded that patients with small epidural hematoma with a fracture overlying major vessels or major sinuses, diagnosed within 24 hours of trauma are at risk of subsequent deterioration and may require surgical evacuation.

Key words: Asymptomatic, Extradural, Hematoma, EDH, Fracture

Bang. J Neurosurgery 2020; 10(1): 20-26

\section{Introduction:}

Extradural hematomas (EDHs) frequently present with rapid neurological deterioration that requires urgent surgical evacuation when indicated, to prevent poor neurological outcome or death. Glasgow Coma Scale score on admission is one of the most important predictors of eventual prognosis in majority of patients. Munro and Maltby40 stated that a favorable outcome could be ensured only if an EDH was evacuated before the onset of brain dysfunction and herniation. Several authors have reported conservative treatment of small sized hematomas with a good outcome.
However, the experimental work of Ford and McLaurin23 indicates that an EDH achieves nearly full size within a very brief period within 3 hours not usually beyond 6 hours and rarely beyond 24 hours after the injury42, which suggests that these lesions do not grow over a period of many hours following the initial injury. The authors emphasized that subsequent neurological decline may be secondary to cerebral edema, hypoxia or impaired cerebrospinal fluid drainage.

A small EDH is called asymptomatic if there is no clinical evidence of raised intracranial pressure and

1. Dr. Sukriti Das, Associate Professor, Department of Neurosurgery, Dhaka Medical College \& Hospital (DMCH)

2. Dr. Dipankar Ghosh, Phase-B Resident, Department of Neurosurgery, Dhaka Medical College \& Hospital (DMCH)

3. Dr. Asit Chandra Sarkar, Professor, Department of Neurosurgery, Dhaka Medical College \& Hospital (DMCH)

4. Dr. Mohammed Shamsul Islam Khan, Assistant Professor, Department of Neurosurgery, Dhaka Medical College \& Hospital (DMCH) Address of Correspondence: Associate Professor Dr. Sukriti Das, FRCS, FCPS, MS, Department of Neurosurgery, Dhaka Medical College \& Hospital, Dhaka. Cell phone: +8801711676848, e-mail: sukriti66@yahoo.com 
no evidence of focal neurological signs by the mass effect from that EDH42.

\section{Materials and Methods:}

A series of 300 small extradural hematomas being admitted after a minor head injury where the surgical point of view was insignificant, were observed in the neurosurgical units of Dhaka Medical College and Hospital, Bangladesh from January 1, 2015 to December 31, 2019.

Our study included patients presented with a GCS 34 score of 14 or 15 showing no neurological deficits. Cases with minor associated cerebral lesions like subdural hematoma, brain contusions were also included, but only if the EDH was small and producing no neurological deficit to the patient. We evaluated the patients clinically with GCS and other symptoms like headache, vomiting, altered consciousness, convulsion and also radiologically with CT scan of head by some parameters like site, thickness and volume of EDH, associated overlying skull fracture, time interval of CT scan from trauma.

\section{Results:}

Table 1 shows the results about the individual characteristics of the study population. There was no exclusion range for age of the patient. Result shows, males were more affected by the condition 202 (67.3\%) and road traffic accident in 175 (58.3\%), was the single most common cause for the head injury.

Other causes reported are fall from height in $75(25 \%)$ cases, physical assault in $40(13.3 \%)$ cases etc. All the patients were conscious and well oriented during admission. GCS 15 was found in $210(70 \%)$ and GCS 14 in $90(40 \%)$ of patients. All patients with GCS 14 had spontaneous eye opening

'E3' which may be due to either pain from primary impact or post traumatic psychological un- wellbeing. Some of these patients subsequently deteriorated clinically and/or radiologically who had concomitant other intracranial insults like contusion, subdural hematomas etc. Most of the patients presented with headache, $145(48.3 \%)$. Other presentations were vomiting in $72(24 \%)$ cases, drowsiness in $35(11.67 \%)$

Table-I

Characteristics of the Study Population ( $n=300)$

\begin{tabular}{llc}
\hline Parameters & Sub group of Parameters & Number of Patients \\
\hline Age & $4.5-50$ years & \\
Sex & Male & $202(67.3 \%)$ \\
Cause of injury & Female & $98(32.7 \%)$ \\
& RTA & $175(58.3 \%)$ \\
& Fall from height & $75(25 \%)$ \\
GCS on admission & Physical assault & $40(13.3 \%)$ \\
Presentation at admission & Others & $10(3.3 \%)$ \\
& 15 & $210(70 \%)$ \\
& 14 & $90(40 \%)$ \\
& Headache & $145(48.3 \%)$ \\
Skull fracture & Vomiting & $72(24 \%)$ \\
Site of impact & Drowsiness & $35(11.67 \%)$ \\
& Cephalo-hematoma & $45(15 \%)$ \\
Time from injury to diagnosis & Irritability & $18(6 \%)$ \\
& Present & $185(61.67 \%)$ \\
& Absent & $115(38.33 \%)$ \\
& Frontal & $60(20 \%)$ \\
& Temporo-parietal & $180(60 \%)$ \\
& Occipital & $30(10 \%)$ \\
& Combined/Others & $30(10 \%)$ \\
& $<24$ hours & $225(75 \%)$ \\
& $24-48$ hours & $54(18 \%)$ \\
& $48-72$ hours & $21(7 \%)$ \\
\hline
\end{tabular}


cases, cephalo-hematoma in 45 (15\%) cases, irritability (in children) was 18 (6\%). Skull fracture was revealed in CT scan of head in 185 (61.67\%) cases. The site of primary impact was temporo-parietal in $180(60 \%)$ cases and frontal in $60(20 \%)$ cases. Most 225 (75\%) patients were diagnosed before 24 hours of trauma. The rest were diagnosed between 24 to 72 hours from trauma.

Table 2 shows CT scan findings of study population. Most of the patients 264 (88\%) had pure epidural hematoma $(E D H)$ followed by EDH with contusion in $18(06 \%)$ cases, EDH with subdural hematoma in 12 (04\%) cases and EDH with subarachnoid hemorrhage in $06(02 \%)$ cases. On the basis of localization on CT scan EDH was temporal in 130 (43.4\%) cases followed by parietal $62(20.6 \%)$, frontal $53(17.6 \%)$, occipital $34(11.4 \%)$ and in combination 21 (07\%). On CT scan of brain maximum thickness of blood hematoma was
$<10 \mathrm{~mm}$ in 117 (39\%) patients and followed by $11-15$ $\mathrm{mm}$ in $92(30.6 \%)$ cases, $16-20 \mathrm{~mm}$ in $45(15 \%)$ cases, $21-25 \mathrm{~mm}$ in $24(08 \%)$ cases and $>25 \mathrm{~mm}$ in $22(7.3 \%)$ cases. No midline shifting was seen in CT scan in $274(91.3 \%)$ patients, maximum

285 (95\%) patients did not have ventricular effacement on CT scan of brain and normal condition of basal cisterns in 289 (96.3\%) patients.

Table 3 shows Deterioration of patients and Intervention. Among 51 patients who deteriorated later, most of the patients $33(11 \%)$ were admitted within 24 hours of trauma. Out of these 19 (6.33\%) patients needed surgical evacuation of hematoma. Among all 300 patients, 291 (97\%) got good recovery and most $266(88.67 \%)$ of them were treated conservatively (Table 4). Among 51 deteriorated patients, 44 (14.67\%) patients got good recovery and most of them 25 $(8.33 \%)$ were treated by surgery (Table 5$)$.

Table-II

CT scan Characteristics of Study Population $(n=300)$

\begin{tabular}{|c|c|c|}
\hline Parameters & Sub group of parameters & Number of \\
\hline \multirow[t]{4}{*}{ Lesion/Associated lesions } & Pure Epidural hematoma (EDH) & $264(88 \%)$ \\
\hline & EDH with Subdural hematoma & $12(04 \%)$ \\
\hline & EDH with Contusion & $18(06 \%)$ \\
\hline & EDH with Subarachnoid hemorrhage & $06(02 \%)$ \\
\hline \multirow[t]{5}{*}{ Localization } & Temporal & $130(43.4 \%)$ \\
\hline & Parietal & $62(20.6 \%)$ \\
\hline & Frontal & $53(17.6 \%)$ \\
\hline & Occipital & $34(11.4 \%)$ \\
\hline & Combination & $21(07 \%)$ \\
\hline \multirow[t]{5}{*}{ Maximum thickness(in mm) } & $<10 \mathrm{~mm}$ & $117(39 \%)$ \\
\hline & $11-15 \mathrm{~mm}$ & $92(30.6 \%)$ \\
\hline & $16-20 \mathrm{~mm}$ & $45(15 \%)$ \\
\hline & $21-25 \mathrm{~mm}$ & $24(08 \%)$ \\
\hline & $>25 \mathrm{~mm}$ & $22(7.3 \%)$ \\
\hline \multirow[t]{2}{*}{ Midline shift (in mm) } & No & $274(91.3 \%)$ \\
\hline & Yes & $26(8.7 \%)$ \\
\hline \multirow[t]{2}{*}{ Ventricular effacement } & Mild & $15(5 \%)$ \\
\hline & No & $285(95 \%)$ \\
\hline \multirow[t]{2}{*}{ Condition of basal cistern } & Normal & $289(96.3 \%)$ \\
\hline & Compressed & $11(3.67 \%)$ \\
\hline
\end{tabular}


Table-III

Deterioration and Intervention of Study Population ( $n=51)$

\begin{tabular}{lccc}
\hline Timing of admission & No. of patients deteriorated & Conservative & Surgery \\
\hline$<24$ hours & $33(11 \%)$ & $14(4.67 \%)$ & $19(6.33 \%)$ \\
$24-48$ hours & $11(3.67 \%)$ & $05(1.67 \%)$ & $06(2 \%)$ \\
$48-72$ hours & $07(2.33 \%)$ & $01(0.33 \%)$ & $06(2 \%)$ \\
\hline Total & 51 & 20 & 31 \\
\hline
\end{tabular}

Table-IV

Outcome: Study Population ( $n=300)$

\begin{tabular}{lccc}
\hline Parameter & Number of Patients & Surgery Group & ConservativeGroup \\
\hline Good recovery without any sequelae & $291(97 \%)$ & $25(8.33 \%)$ & $266(88.67 \%)$ \\
Good recovery with minor sequelae & $05(1.67 \%)$ & $04(1.33 \%)$ & $01(0.33 \%)$ \\
Death & $04(1.33 \%)$ & $02(.67 \%)$ & $02(0.67 \%)$ \\
\hline Total & 300 & 31 & 269 \\
\hline
\end{tabular}

Table-V

Outcome: Among Deteriorated Patients (51 patients):

\begin{tabular}{lccc}
\hline Parameter & Number of patients & Surgery group & Conservative group \\
\hline Good recovery without any sequelae & $42(14 \%)$ & $25(8.33 \%)$ & $17(5.67 \%)$ \\
Good recovery with minorsequelae & $05(1.67 \%)$ & $04(1.33 \%)$ & $01(0.33 \%)$ \\
Death & $04(1.33 \%)$ & $02(.67 \%)$ & $02(0.67 \%)$ \\
\hline Total & 51 & 31 & 20 \\
\hline
\end{tabular}

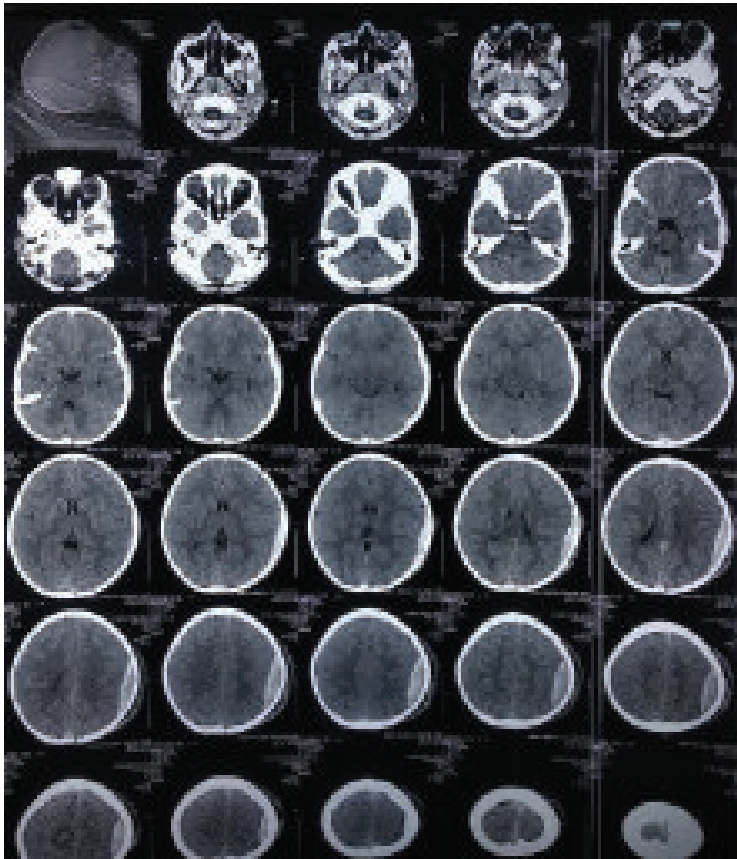

a

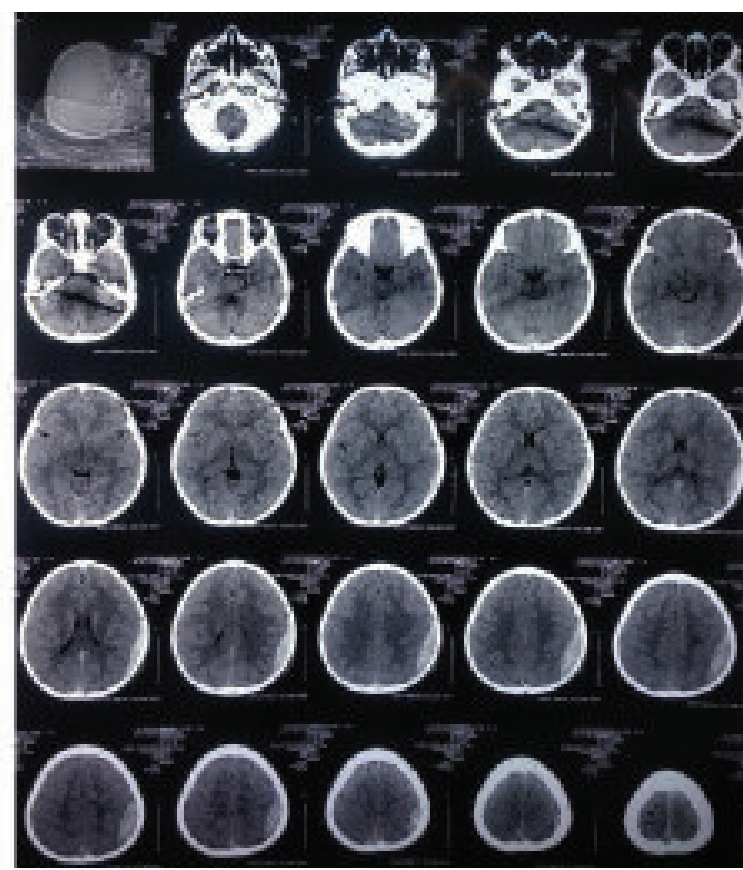

b

Fig.-1 (Patient 1): Hematoma did not increase in size. Patient was treated conservatively. (a) CT head on admission (b) CT head on 3rd post admission day. 


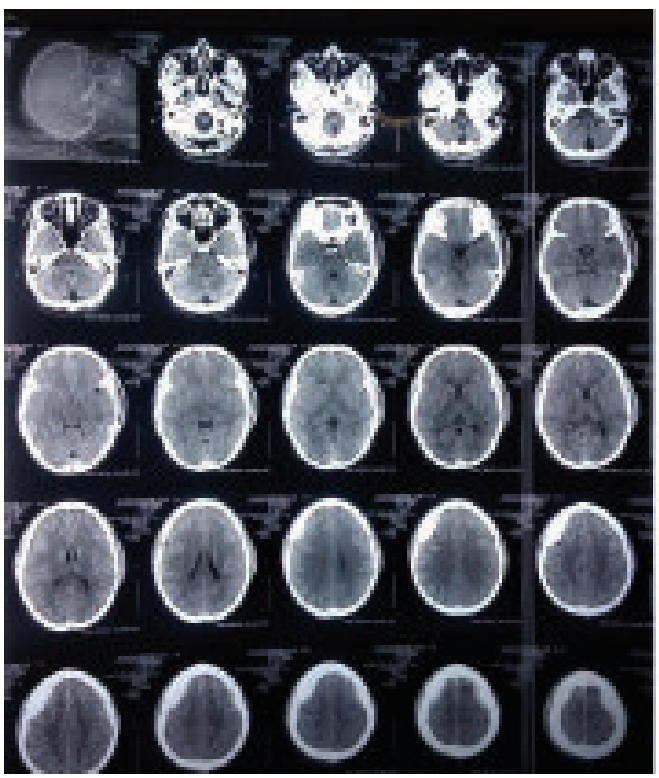

a

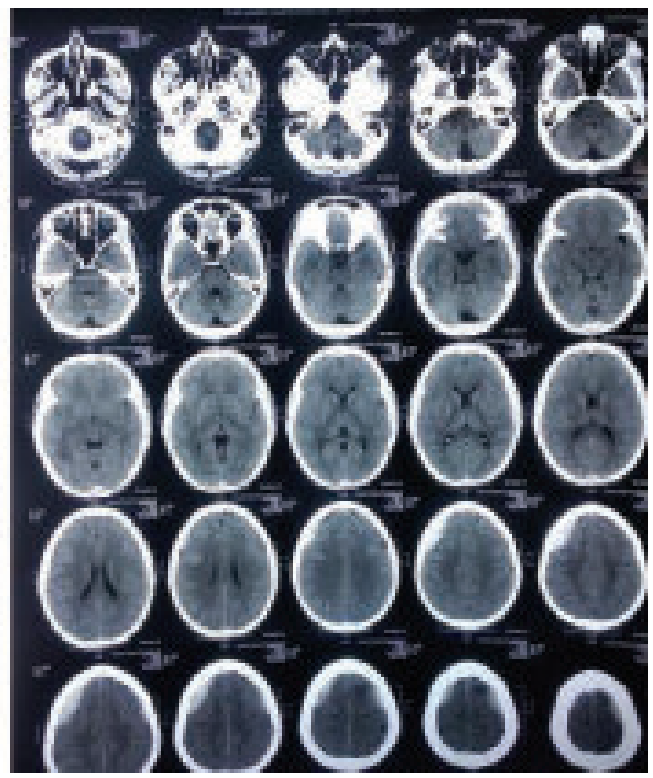

b

Fig.-2 (Patient 2): Hematoma increased in size but surgery was not required. Patient was treated conservatively. (a) CT head on admission, (b) CT head on 3rd post admission day.

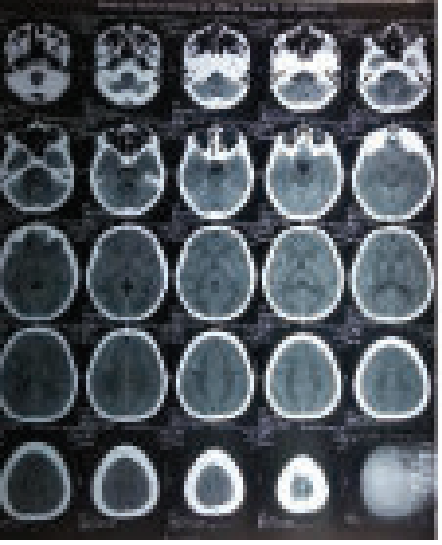

a

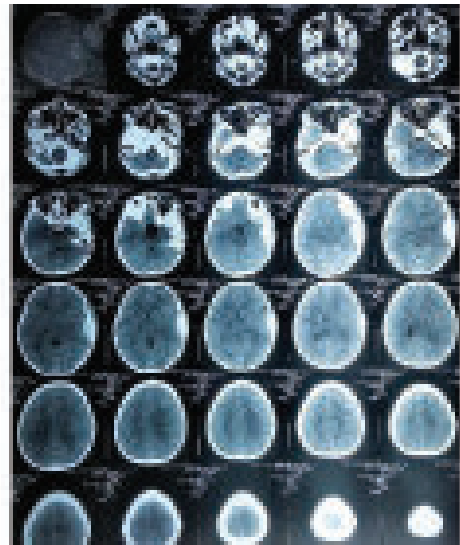

b

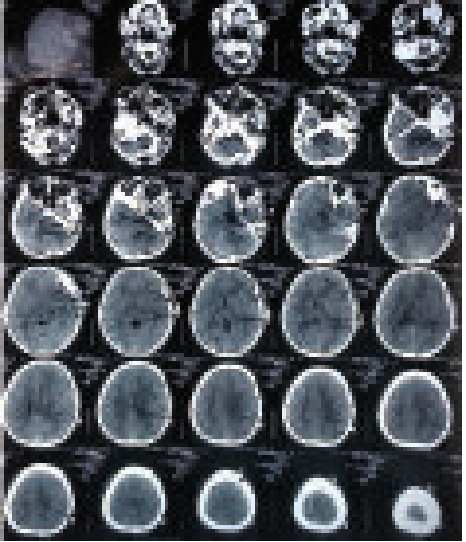

C

Fig.-3 (Patient 3): Hematoma increased in size and patient deteriorated clinically. Surgical evacuation was done. (a) CT head on admission (b) CT head on 3rd post admissionday (c) CT head 2nd Post-operative day.

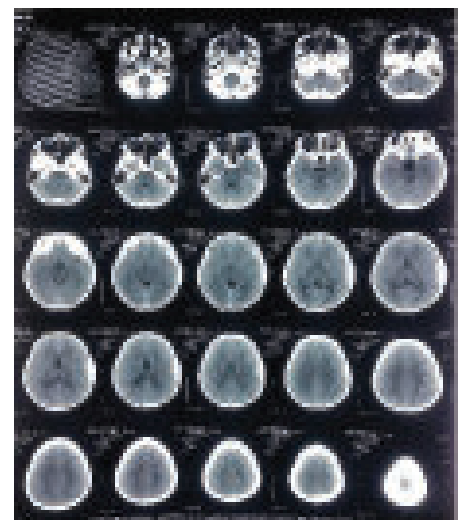

a

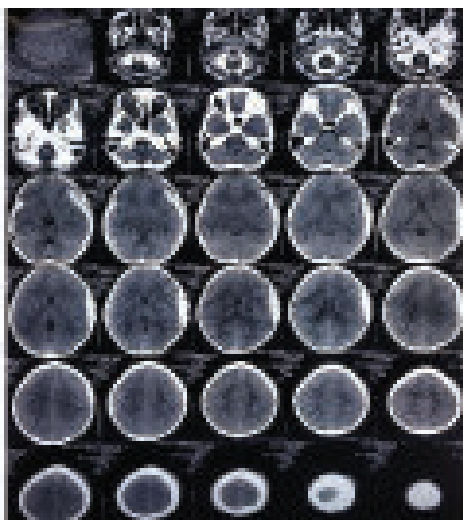

$\mathrm{b}$

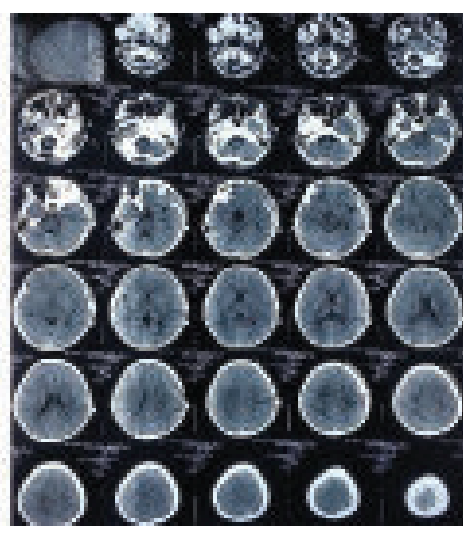

C

Fig.-4 (Patient 4): Hematoma increased in size and patient deteriorated clinically. Surgical evacuation was done. (a) CT head on admission (b) CT head on 4th post admission day (c) CT head 1st Post-operative day. 


\section{Discussion:}

At first this possibility was attributed to a venous origin of the hematoma that would allow the brain to slowly adapt itself to its presence. Patients having admitting GCS 14-15 with EDH $<1 \mathrm{~cm}$ thickness without any midline shift on CT scan of head can be treated conservatively with excellent outcome in majority of cases44. Later, McLaurin and Ford23 suggested that the lack of clinical symptoms was not correlated to this venous origin. In fact, they believed that an extradural hematoma has nearly always an arterial origin and it reaches its definitive size within minutes or at the most within hours3. The clinical manifestation20 is the result of the summation of several factors such as the size of the clot, its location and the individual brain tolerance to its presence. Pozzati15 suggested the possible interaction of the two factors (arterial and venous) provided the bleeding sources are of "low tension", while Iwakuma11 thinks bleeding of arterial origin prevails in younger patients. The incidence of delayed extradural hematoma (DEDH) following an initially negative CT scan of head is reported in $10-30 \%$ cases 43 .

Temporal and temporo-parietal localizations are present in $>64 \%$ of our "asymptomatic" cases. This percentage is near to the incidence of temporal localizations in other series of extradural hematoma (in any clinical condition) reported in the CT era. As early as in 1980 Shields33 speculated that some hematoma may undergo spontaneous re-absorption without surgical evacuation. More recently, several studies $3,24,28,35,36$ confirmed that a selected number of patients may be treated conservatively with success.

The mechanism of hematoma reabsorption was correlated with the formation of a fibrovascular neomembrane functioning as an absorption structure. This process requires many days, with the fastest described as completed in 13 days 26 , and may undergo periods of expansion between the fifth and the fifteenth day24 but we observed the patients for 72 hours. The decision not to operate on hematomahaving a maximum thickness of less than $10 \mathrm{~mm}$ with a midline shift of less than $5 \mathrm{~mm}$ appears as safe in terms of the results obtained.

Temporal location of the hematoma ( $>43 \%$ in our series) does not allow large lesions to remain asymptomatic rather subsequently may enlarge in size and require surgery. We think that, facing the challenge of an early diagnosis of asymptomatic extradural hematoma, it is necessary to follow the patients with serial clinical evaluation and CT scan of head (particularly on day 1 , day 3 and sometimeson day 5) to see expansion of hematoma and/or clinical deterioration. In our series, skull fracture was present in the $(61.67 \%)$ of patients in CT scan of head. Many of these patients may harbor an $\mathrm{EDH}$ underlying the fracture but that may deteriorate the patient as the fracture transmit intracranial pressure towards exterior. To conclude, our study seems to indicate that, extradural hematoma in patients with minor head injury are benign lesions that can be treated conservatively in a well-selected group of cases. Early diagnosis of this recognized disease and successful conservative management is possible in a large number of cases but will require close follow up to see whether there is expansion of hematoma size and/or clinical deterioration of patients especially in early period of the disease.

Conclusion: Small EDHs should not be always ignored and kept on the floor or corridor unattended. They also should not be overlooked in outpatient department or discharged immediately after admission. Rather they should have a close follow up clinically through GCS score, time since trauma and diagnosis and also radiologically through CT scan of head to see whether the hematoma is expanding or not. Considering all these, it is concluded that patients with small epidural hematoma

- Diagnosed within 24 hours of trauma

- With a fracture overlying major vessels or major sinuses may deteriorate subsequently and require surgical evacuation.

\section{Reference:}

1. Bricolo P, Pasut LM (1984) Extradural hematoma: toward zero mortality. Neurosurgery 14:8-12

2. Briggs M, Clarke P, Crockard A, Cummings B, Galbraith S, Garfield J, Jeffreys R, Jennett B, Kalbag R, Mendelow AD, Miller JD, Price D, Taylor J, Uttley D (1984) Guidelines forinitial management after head injury in adults. Br Med $\mathrm{J}$ 288:983-985

3. Bullock R, Smith RM, Van Dellen JR (i985) Nonoperative management of extradural hematoma. Neurosurgery 16 : 602-606

4. Cooper PR (1986) Spontaneous healing of acute extradural hematoma. Comment. Neurosurgery t8:700

5. Cordobes F, Lobato RD, Rivas JJ, Munoz M J, Chillon D, Portillo JM, Lamas E (1981) Observation on 82 patients with extradural hematoma. J Neurosurg 54:179-186 
6. Dacey RG, Wayne AM, Rime IRW, Winn R, Jane JA (1986) Neurosurgical complication after apparently minor head injury: Assessment of risk in a series of 610 patients. J Neurosurg 65:203-210

7. Devaux B, Roux FX, Chodkiewicz JP (1986) L'h matome extradurala l'\&e du S.A.M.U. et du scanner. Neurochirurgie 32:221-2258. Gennarelli TA, Spielman GM, Langfitt TW, Gildenberg PL,Harrington T, Jane JA, Marshall LF, Miller JD, Pitts LH (1982)Influence of the type of intracranial lesion on outcome from severe head injury. J Neurosurg $56: 26-32$

9. Heiskanen O (1975) Epidural hematoma. Surg Neurol 4:232610. Hirsh LF (1980) Chronic epidural hematomas. Neurosurgery 6:508-512

10. Hooper RA (1959) Observation on extradural haemorrhage. BrJ Surg 47:7187

11. Iwakuma T, Brunngraber CV (1973) Chronic extradural hematomas: A study of 21 cases. J Neurosurg 38:488493

12. Jackson JJ, Speakman TJ (1950) Chronic extradural hematoma.J Neurosurg 7:444-447

13. Jamieson KG, Yelland JDN (1968) Extradural hematoma: report of 167 cases. J Neurosurg 29:13-23

14. Jennett B, Bond M (1977) Assessment of outcome after severe brain damage: A practical scale. Lancet i: 878-881

15. Pozzati E, Tognetti F: Spontaneous healing of acute extradural hematomas: study of twenty- two cases. Neurosurgery 18:696-700, 1986

16. Jennett B (1980) Skull X-rays after recent head injury. Clin Radiol31:463-469

17. Kaufmann H (1984) Spontaneous resolution of chronic epidural hematomas. Comment. Neurosurgery 15:100

18. K varnes TL, Trumphy JH (1978) Extradural haematoma: report of 132 cases. Acta Neurochir (Wien) 41:223-231

19. Marshall LF, Toole BM, Bowers SH (1983) The national coma data bank. Part. 2: Patients who talk and deteriorate: implication for treatment. J Neurosurg 59:285 288

20. Mc Kissock W, Taylor JC, Bloom WH, Till K (1960) Extradural hematoma: observation in 125 cases. Lancet 2:167-172

21. Mc Laurin RL, Ford LE (1964) Extradural hematoma: Statistical survey of 47 cases. J Neurosurg 21:364-371

22. McLean A, Temkin N, Dikmen S, Wyler A (1983) The behavioral sequelae of head injury. J Clin Neuropsichol 5: 361376

23. Miller JD (1986) Minor, moderate and severe head injury Neurosurgery 9:135-139

24. Ford LE, McLaurin RL: Mechanisms of extradural hematomas. J Nenrosurg 20:760-769, 1963

25. Pagni CA (1968) L'ematoma extradurale. Risultati del trattamento chirurgico di una serie di 127 casi. Monografia. Milano,Quattrocchi, pp 1-79

26. Pang D, Horton JA, Herron JM, Wilburger JE, Vries JK (1983) Neurosurgical management of extradural hematomas in children.J Neurosurg 59: 958-971
27. Pozzati E, Frank F, Frank G, Gaist G (1980) Subacute and chronic extradural hematomas. A study of 30 cases. J Trauma20:795-799

28. Pozzati E, Tognetti F (1986) Spontaneous healing of acute extradural

29. hematoma: study of 22 cases. Neurosurgery 18:69700

30. Pozzati E, Staffa G, Nuzzo G, Frank F (1987) Late recurrence of bleeding in a chronic extradural hematoma. J Trauma 27:579 58031. Rimel RW, Giordani B, Barth JT, Boll TJ, Jane JA (1981) Disability caused by minor head injury. Neurosurgery 9: 221-228

32. Sakai HS, Takagi H, Ohtaka H, Tanabe T, Ohwada T, YadaK (1988) Serial changes in acute extradural hematoma size and associated changes in level of consciousness and intracranial pressure.J Neurosurg 68:566-570

33. Servadei F, Piazza G, Seracchioli A, Acciarri N, Pozzati E, GaistG (1988) Extradural hematomas: an analysis of the changing characteristics of patients admitted from 1980 to 1986 . Diagnostic and therapeutic implications in 158 cases. Brain Injury 2:87-100

34. Servadei F, Ciucci G, Pagano F, Rebucci GG, Ariano M, PiazzaG, Gaist G (1988) Skull fracture as a risk factor of intracranial complications in minor head injuries. J Neurol Neurosurg Psychiatry51:526-528

35. Shields CB (1980) Chronic epidural hematomas. Comment. Neurosurgery6:512

36. Teasdale G, Jennett B (1974) Assessment of coma and impaired consciousness: a practical scale. Lancet 2:8184

37. Tochio H, Waga S, Tashiro H, Takeuchi T, Mcyazaki M (1984) Spontaneous resolution of chronic epidural hematomas: report of three cases. Neurosurgery 15:96100

38. Weaver D, Pobereskin L, Jane JA (1981) Spontaneous resolution of epidural hematomas. Report of two cases. J Neurosurg 54:248-251

39. Bullock R, Smith RM, van Dellen JR: Nonoperative management of extradural hematoma. Neurosurgery 16 : 602-606, 1985

40. MunroD, Maltby GL:Extradural hemorrhage.A study of forty-four cases. Ann Surg 113:192-203,1941

41. Ericson $\mathrm{K}, \mathrm{H} \sim$ kansson $\mathrm{S}$ : Computed tomography of epidural hematomas. Association with intracranial lesions and clinical correlation. Acta Radiol 22:513-519, 1981

42. Knuckey, NW. Gelbard, S. and Epstein, MH. (1989) The management of "asymptomatic" epidural hematomas A prospective study. J Neurosurg, 70(3), 392-396

43. Prajapati DV, Shah NJ. Outcome of traumatic Extradural Hematoma (EDH) using Glasgow Outcome Scale (GOS). Int Surg J 2018; :33,27-34.

44. Haider et al. Outcomes in Trauma Patients with Isolated Epidural Hemorrhage: A Single- Institution Retrospective Cohort Study. Southeastern Surgical Congress 2016;82, $1209-1214(6)$ 